\section{Training in Obstetrics and Gynaecology: The Essential Curriculum}

Ippokratis Sarris, Susan Bewley, Sangeeta Agnihotri (eds). Oxford, UK: Oxford University Press, 2009. ISBN-13: 978-0-19921-847-9. Price: £39.95. Pages: 528 (paperback)

This textbook was produced to reflect changes in the curriculum brought in by the Modernising Medical Careers the (MMC) programme, which affects how doctors study and train in the UK. The book has multiple contributors, comprising both UK trainees and consultants collaborating to reflect changes brought by the MMC and the consequent new Royal College of Obstetricians and Gynaecologists' (RCOG) training curriculum, which gives this book a wide perspective.

Each chapter in this textbook covers a topic or subject in a compact way, and comprises one or two pages of essential nuggets of information. The descriptive text is augmented with carefully selected figures, tables, flow charts and text boxes that highlight key concepts or points, and where applicable practical surgical skills (e.g. administering a pudendal block, performing a Caesarean section, dealing with imperforate hymen, or undertaking a 'straight' hysterectomy). The textbook covers topics in a sequence that generally reflects a woman's journey from conception, her childhood, teenage years, youth, middle age, and to her eventual menopause and later life.

Most chapters (though not all) have a small list of references or a reading list. A significant number of chapters include information on recent advances, for example, pelvic organ prolapse, guidance issued by the National Institute for Health and Clinical Excellence (NICE) or the RCOG (e.g. induction of labour). Conversely, there were chapters that covered only the bare essentials, for example, gynaecological malignancies. Controversies and debates about 'grey' areas are not well covered in either obstetrics (e.g. induction of labour in previous Caesarean section or use of rotational forceps) or in gynaecology (e.g. modalities of treatment for endometriosis, assisted conception or treatment of early endometrial cancer).

There is a chapter on non-clinical professional skills, which is essential in the current climate (e.g. domestic violence, bereavement or when things go wrong). It provides information on communication, teamwork and confidentiality. There is also a section, albeit a succinct one, on critical appraisal of the literature - an important component in the training of current and future clinicians. This chapter about non-clinical professional skills stands out in what would be an otherwise standard textbook aimed at junior trainees within the specialty (premembership and preparing for the second part of the MRCOG).

The book would also be useful to keen medical students and allied health professionals who wish to study the specialty in depth but who do not want to read a daunting textbook. The textbook closes with examples of case-based discussion of common obstetric and gynaecological presentations that draw on the material in the previous chapters.

This textbook, although it does have some shortcomings, covers all the essential topics required for trainees, not just for the MRCOG examination but also to give a sound foundation for subsequent clinical practice. It has the right balance, and the chapter on non-clinical professional skills is especially refreshing and timely. I would thoroughly recommend it.

Reviewed by Honest Honest

Consultant in Obstetrics and Gynaecology, Heart of England Foundation NHS Trust (HEFT), Birmingham, UK

J Fam Plann Reprod Health Care 2011;37:116. doi:10.1136/ffprhc.2010.0024 